Volume 3, 2003

\title{
Sources of inspiration in industrial practice: The case of knitwear design
}

\author{
Claudia Eckert \\ Engineering Design Centre \\ Department of Engineering \\ University of Cambridge
}

\author{
Martin Stacey \\ School of Computing \\ De Montfort University
}

\begin{abstract}
Drawing ideas from previous designs and other sources of inspiration is a universal part of all human designing, but the forms that adaptation takes, and the ways it is conceptualised both differ between industries. This paper describes how sources of inspiration are used in commercial knitwear design. Knitwear designers actively search for sources of inspiration, which they use both to define the space of designs that will meet their purposes and tune their tacit perceptions of what is appropriate, and in the development of individual designs. They employ active strategies for guiding their idea generation actions to produce the ideas the situation requires. Knitwear designers routinely use a very broad range of sources of inspiration, and are explicitly aware and open about how they use them. Identifying a good source is often the key creative step in knitwear design, and being able to do this well is a vital skill for a designer. The paper makes some provisional generalisations about the structure of design processes driven by thinking with sources of inspiration, to provoke and facilitate comparisons with other industries.
\end{abstract}

Keywords: inspiration, adaptation, design reuse, design process, knitwear. 


\section{Introduction: Adaptation is ubiquitous}

Designing by adapting earlier designs and by drawing ideas and solution principles from earlier products is ubiquitous in all fields of design. The form this borrowing takes differs between industries, as does the way borrowing is conceptualised. The cognitive mechanisms that underlie design thinking - and make borrowing an integral part of designing - are shared by all designers. But industries differ radically both in the demands designs must meet and the cultural context in which designing is done - in attitudes and values as well as skills, shared experiences and social organisations. What roles do sources of ideas play in designing - and what are the commonalities and differences between different types of designing?

In this paper we show how sources of inspiration are used in the practice of commercial knitwear design, and propose some generalisations to be tested against observations of other types of designing. This paper views knitwear design as a sequence of activities that use and create information; it is intended to complement our analysis, published elsewhere (Eckert and Stacey, 2001), of the cognitive and social mechanisms through which knitwear and fashion designers collectively create fashion. It is also complementary to our more detailed discussions of the procedures by which knitwear designers adapt sources of inspiration in creating individual designs (Eckert and Stacey, 2003), and how knitwear designers communicate their design ideas to knitting machine technicians (Eckert, 2001).

The commercial design of knitted garments is a process that shares many important characteristics both with other types of aesthetic design and with engineering (Eckert, 1997b, 2001); it is complex enough to be interesting both in its own right and for its parallels to other industries, while being simple enough to understand as a whole. Aesthetic design of form, requiring the sensitivity to fashion context and Zeitgeist of product design, interacts with structural design involving technical considerations similar to those in engineering.

Section 2 introduces the knitwear industry and outlines our research on the knitwear design process. In section 3 we describe the major types of sources of inspiration used by knitwear designers. Section 4 reports our observations of how knitwear designers use sources of inspiration in their designing activities. In section 5 we abstract and generalise from these observations, as well as from other studies of design, to present some consistent patterns in the use of sources of inspiration in designing in forms that can be compared to other models of design processes and to observations of design in other industries.

\section{The knitwear industry}

The design and production of knitted garments is a major industry in several European countries, as well as in many other parts of the world. It is a very important part of the textile industry. While most western European knitwear companies are moving their production to eastern Europe or Asia, they still design in Europe. 


\subsection{A small-scale complex design process}

Knitwear design combines artistic and technical design. It is driven by the need to achieve specific aesthetic effects within a complex and rapidly changing cultural context. It combines generating the fabric, the field of fabric design, with the generation of shape, the field of fashion design. Creating structures that achieve particular emergent aesthetic effects can sometimes be a difficult challenge, and small changes to a knitted structure can have dramatic effects on its appearance and on the cost or feasibility of knitting it (see Spencer, 1989, for a discussion of technical issues in knitwear design). Moreover yarn properties vary not just with the type of fibre but also with the dyes used and even the temperature and humidity of the factory, so there is a complex interaction between aesthetic and technical design. Garments need to be produced to tight price points, as well as rigid deadlines dictated by when a new season's clothes go into the shops. In consequence knitwear design is complex enough to share some of the characteristics of complex engineering design, while being simple enough to allow us to observe every stage of the design process, compare different companies, and acquire a significant part of the designers' expertise.

Most commercial knitwear design is done by multidisciplinary design teams whose members have very different backgrounds and expertise; although small they exhibit many of the problems encountered by multidisciplinary teams in other industries (Eckert, 2001). The process is typically shared between knitwear designers, who are responsible for the aesthetic aspects of the design, and the knitting machine technicians, who use sophisticated CAD systems to program computer-controlled knitting machines to produce the garments. The knitting machine technicians do a lot of detailed design in the course of turning the knitwear designers' specifications into the exact descriptions of garment pieces from which the programs are compiled; however no one in the industry thinks of what the technicians do as designing.

In the United Kingdom, knitting machine technicians are almost always male, seldom have any education beyond secondary school, even though they are doing challenging programming jobs, and are trained by their employers, with whom they usually remain for a long time. By contrast knitwear designers are typically female, almost always have degrees in design, and usually don't remain with one company for more than a few years (Eckert and Stacey, 1994). (Hence our use of 'she' for knitwear designers.) The United Kingdom is the only European country with university degree courses dedicated to knitwear design; British knitwear designers can be found in many European countries especially Italy, and overseas students take British knitwear design degrees. However in Britain as elsewhere many knitwear designers were originally trained in fashion design (the design of tailored clothes).

\subsection{Our study}

The central strand of our research was a series of visits by the first author to 25 knitwear companies in Britain, Germany and Italy between 1992 and 1997, ranging from hour-long interviews to week-long observations of day-to-day designing activities. She interviewed or observed more than 80 designers and technicians. Wherever possible designers were observed doing their everyday activities, but in some companies the designers felt that an interview was a better use of their time. Designers 
in the knitwear industry are used to students visiting companies and observing what they do, so she found it easy and natural to adopt an apprentice or agony aunt role. The design time for a single garment can be measured in hours rather than months or years, so within a few days it is possible to see different designs in various stages of maturity, or follow a particular design through a significant part of its development. In addition the first author attended knitwear design classes at De Montfort University in Leicester, England, and knitting machine programming courses at Universal GmbH in Westhausen, Germany.

The first sequence of observations was aimed primarily at understanding the potential for intelligent computer support for knitwear design; it focused on the tasks designers and technicians perform and the knowledge and skills they require, and on the communication between designers and technicians. This research led ultimately to the development of a prototype computer tool for garment shape specification that enables designers to create unambiguous and technically correct shape specifications quickly and easily (Eckert, Cross and Johnson, 2000; Eckert and Bez, 2000; Eckert, 2001). The designers we observed used sources of inspiration throughout their designing activities, and discussed them in interviews. Our observations of the ubiquitous use of sources of inspiration led to a further research project (MinD - Mechanisms of Inspiration in Novel Design) focusing on that issue, and a second sequence of visits to knitwear manufacturers. As part of the Mind project we also ran an experiment in which designers were given a sources of inspiration from which to create designs (Eckert and Stacey, 2003; see section 4.3). The debriefing after the experiment included a general discussion of how the subjects used sources of inspiration in their work.

The companies were selected to give a representative cross-section of the industry in Britain and Germany. They ranged from the suppliers of cheap mail-order companies to some of the world's most prestigious knitwear companies. As far as possible we looked at direct competitors, to differentiate between the effects of the way a company was run, and the consequences of the constraints placed on it by its position in the market; Eckert and Demaid (2001) discuss the influence of different business models on design processes in textile industries. In particular we studied several competing suppliers to the British retailer Marks and Spencer. In each company we attempted to get a balanced view by observing or interviewing several designers, or designers and technicians working on the same design.

The observational studies took an ethnographic approach (see Hammersley and Atkinson, 1995; Agar, 1980, for introductions to ethnography). The first author sought to develop the perspectives and perceptions of the participants in the knitwear design process, while retaining the analytical perspective of a knowledge engineer, and actively exploring issues and testing hypotheses. Although the research differed in focus from most ethnographic studies, it fitted the standard ethnographic paradigm (described by Atkinson and Hammersley, 1994; Hammersley and Atkinson, 1995): it was an openended exploration of the nature of the design process, not tied to specific prior hypotheses, which included focused observations and questions to test hypotheses derived from previous observations. The study employed a model-driven approach to analysing design processes in terms of the information created and transmitted by design activities (Stacey and Eckert, 1999), resulting in a very detailed activity sequence model (Eckert, 1997b), as well as an analysis of how information is transmitted between the participants (Eckert, 1997b, 2001). 


\section{Sources of inspiration for knitwear design}

Knitwear designers use a variety of objects as sources of inspiration, and use them for a range of purposes. Anything visual can be a source of inspiration for a design, from a John Galliano garment to a plate of baked beans. Designers are mainly interested in the visual appearance and connotations of the objects, and seldom in the conceptual integrity of the design. Different sources of inspiration can be combined in one garment: a designer garment, a Roman ornament, a piece of tree bark.

While any kind of object might be used for many of these purposes, and a single source of inspiration can be used in different ways at different points in the design process, there are fairly consistent roles for particular types of objects. In this section we describe the most common sources, and the roles they play in the sequence of major designing activities. We found these patterns to be remarkably stable across the industry; in section 4.4 we discuss the commonalities and differences between companies.

Garments. All designers at all levels of the market make use of knitted and tailored garments as sources of inspiration. Designers look at competitors' products, as well as their own past designs from recent collections or ancient company archives. Looking at the garments from market leaders gives the designers a tacit understanding of fashion development and new technical features. All the contemporary garments that designers see collectively define the envelopes of acceptable designs within particular fashions, while giving designers a set of design elements for their new designs (see Eckert and Stacey, 2001).

Features of garments or even entire garments are used to inform new designs directly. A fashionable feature often gives little scope for variation. Reusing other designers' ideas and design elements is ubiquitous in all fields of textiles. It is perceived across the industry as drawing inspiration from another design rather than copying. Designers often look for elements in other designs that would allow them to realise an idea. Copying is more of an issue when designers recreate the overall style and appearance of a design, without exactly copying its individual elements. Copyright law provides inadequate protection, not least because innovative small companies cannot afford to sue (Dickson and Coles, 1998); and it is extremely difficult to prove that a design is copied - which is copyright violation - rather than based on the same publicly accessible source of inspiration - which is perfectly fair.

Shape features from tailored garments and motifs from prints are translated into knitwear designs. Shape features of knitted garments and structural patterns such as cables are copied or slightly modified, or recreated in different materials and gauges (yarn thicknesses). On shopping trips the designers look at garments carefully and take measurements - often they get close to being thrown out of shops. Knitwear designers also make use of swatches (pieces of knitted fabric), that they get from knitting machine manufacturers or from spinners (yarn manufacturers), or buy through specialised agencies, who buy mainly from students or freelance designers. Actual garments enable designers to study designs and technical features in detail. Only a real garment or a swatch can be taken apart to reverse engineer its construction. 
Fashion Photographs. All designers study fashion photographs from catwalk shows in magazines such as Collectioni, or on CD-ROM. They flick through fashion magazines, such as Vogue or Elle, pulling out images of everything that takes their fancy, either as inspiration for specific designs or as images to encapsulate a particular mood. A fashion photograph rarely shows details as clearly as the real thing; therefore it is less well suited to reverse engineering the design. Designers sometimes take more functional shots of garments to capture details. However, a fashion photograph provides a clearer indication of the mood of the garment, its context within a collection and the projected image of the target customer.

Artefacts, and images of them. Knitwear designers look for decorative patterns, such as repeat patterns, ornaments, and motifs, in objects such as tiles and mosaics. Typically they pick out parts of a non-knitted design and translate them into imagined or sketched pieces of knitwear. Other textiles are often used as sources of inspiration for patterns. For instance embroideries, carpets and ties can be rich sources of ornamental patterns. Knitwear is often co-ordinated with other textile ranges produced by the same manufacturer or retailer. It is often seen as a strong but subsidiary part of a collection. Knitwear designs are often based on textile prints in the same collection. Designers frequently use historical designs, such as William Morris wallpaper. On shopping trips knitwear designers also buy other textiles such as ties or tights as inspirations. Designers use art and design books frequently. They collect ornament books, such as the copyright-free series published by Dover in the United States, with hundreds of pictures of the same type of object. Paintings and other artworks can also be rich sources of ideas, and everyday things like sweet wrappers or buildings can also be useful.

Nature, and images of it. Many themes take their inspiration from nature. Designers are inspired by animals, plants and other natural objects, as well as natural phenomena such as thunderstorms or sunsets. Designers collect portable physical objects like leaves or shells, use photographs or work from memory. These are used in a similar way to other design objects with designers picking out elements and translating them into knitwear designs.

Yarns. As in other kinds of design, the materials designers plan to use exert a profound influence on the ideas they generate. Knitwear designers are attracted to the texture, the feel, the colour and the overall appearance of a yarn. They comment that a yarn often suggests a design to them; and they sometimes work specifically on designs to use yarns that they liked. The set of available yarns also imposes strong constraints on the knitwear designers, because only a few companies ever have yarns developed for them. In particular this restricts the range of colours designers can use. Yarns are designed up to three years before garments they are employed in reach the shops. Yarn designers depend very heavily on commercially available fashion forecasting materials. Fashion colours are determined by the Color Marketing Group, an American forecasting bureau comprising an international body of experts from various field of design, who look at trends, pick up on likely themes, and assess new technical developments in dyes. They suggest a range of colours, which are then picked up by the forecasting bureaux, spinners, and fabric designers, who work very early in the development of new fashions. Although other colours are added these early predictions determine the overall colour range for a season. 
Objects or images are often used to put colour schemes together. Designers select typically about five colours that they like from the much larger range present in the source. If the colour combination had an effect that designers liked in the original object or image, they can recreate this impression in their own design, and can use these colours to extend their colour palette, if required. Very few designers are able to put colour schemes together without referring to objects or images.

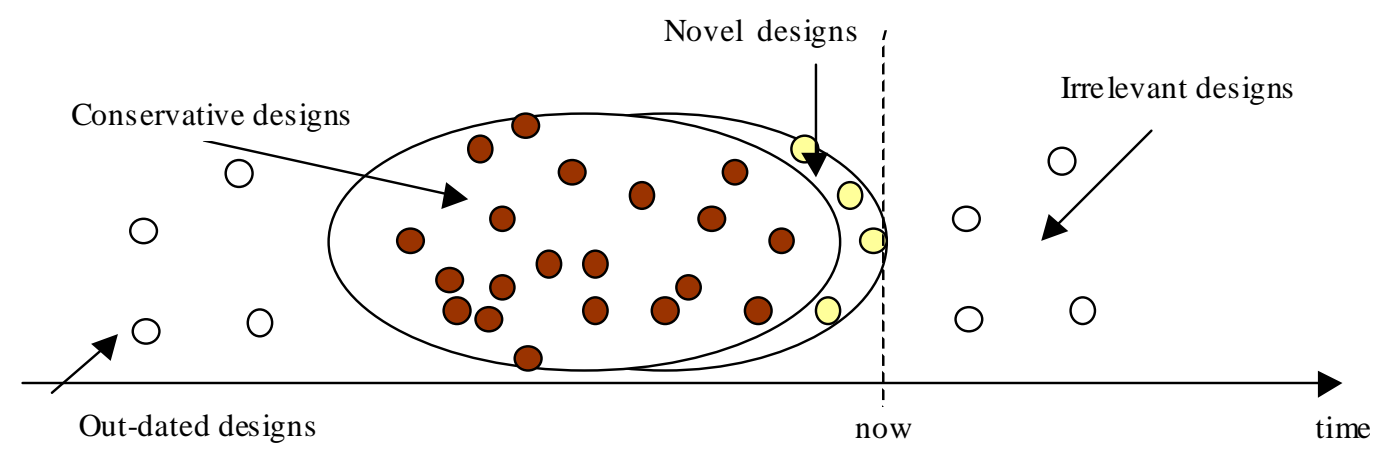

Figure 1 The envelope of acceptable designs within a fashion

\section{Sources of inspiration through the knitwear design process}

Knitwear designers are always looking out for sources of inspiration, and sources of inspiration play a variety of significant roles throughout the design process. In this section we first outline the knitwear design process describing what roles different types of source play at each stage, then we go back to discuss the selection of sources of inspiration for individual designs, and how different kinds of source are adapted to create different kinds of design elements.

\subsection{The stages of the design process}

Figure 2 shows the major stages in the knitwear design process, with the types of sources that are most frequently used at each stage.

Opportunistic Source Hunting. Finding and selecting sources of inspiration for individual designs is neither clearly separated from researching the context of fashion, nor limited to any particular time. All the knitwear designers we interviewed commented that they are constantly looking out for objects that inspire them, and complain that if they don't have frequent exposure to unusual objects, for example through trips to art galleries, they run out of ideas. They collect potential sources of inspiration privately throughout their entire professional life in a more or less systematic way. Many designers also pull images out of magazines whenever they can, independently of their current design tasks. Many designers keep these collections of sources visible or close at hand in their offices to facilitate their use in generating ideas when designs are required.

Fashion Research. When they begin working on each new season, designers need to gain an understanding about what will be fashionable for this season. They need to learn the constraints of the fashion space by understanding what looks dated and what 
is not yet right for their market sector, as well as the key looks and features that define a particular fashion. This understanding of the envelope of what is acceptable, and what appears relatively sober, daring, sexy, and so on within it (see Figure 1), is gained primarily by looking at the clothes presented on catwalks and in the shops. Knitwear designers study catwalk fashion primarily by reading magazines and forecasting materials, looking for themes, colours and styles that are coming through, and picking up on prevalent and novel features. Fashionable features appear earliest in the products of the most upmarket companies, and persist over more than one season, so that it is possible to extrapolate from the fashion of the current season. Designers go on shopping trips to the fashion capitals, such as Milan, Paris, London and New York, to study new collections for themselves and get a feeling for the acceptance of styles in different market sectors. On shopping trips they buy or study key garments which they use in detailed design later on. Knitwear designers typically attend yarn shows where spinners present their ranges in the colours they have selected for the season. Many knitwear designers comment that at yarn shows they gain a feeling for a new season in a day and often begin to translate yarns that they see into specific designs. Senior designers comment that the greatest skill in a knitwear designer is to be able to spot trends and mentally translate them into garments. As the new season approaches, designers' understanding of the range of options available to them in their market segment becomes progressively narrower and more clearly defined.

By doing fashion research, designers are consciously applying procedures, recognised as valuable and expected of them within the designers' culture, for identifying categories of designs and the similarity relationships they embody, as well as for equipping themselves with memories of an updated repertoire of design features (see Eckert and Stacey, 2001, for a discussion of designers' memories for garments). As Schön (1983; Schön and Wiggins, 1992) and Goldschmidt (1991, 1994) among others have found for architects and other visuospatial designers, knitwear designers' perceptions of the characteristics of their own and other designs play an integral role in their idea generation process. By doing fashion research designers tune the tacit perceptual skills they have developed for recognising what is and is not fashionable, what cultural connotations a garment will have, and in what way a garment design needs to be modified to conform to fashion. 


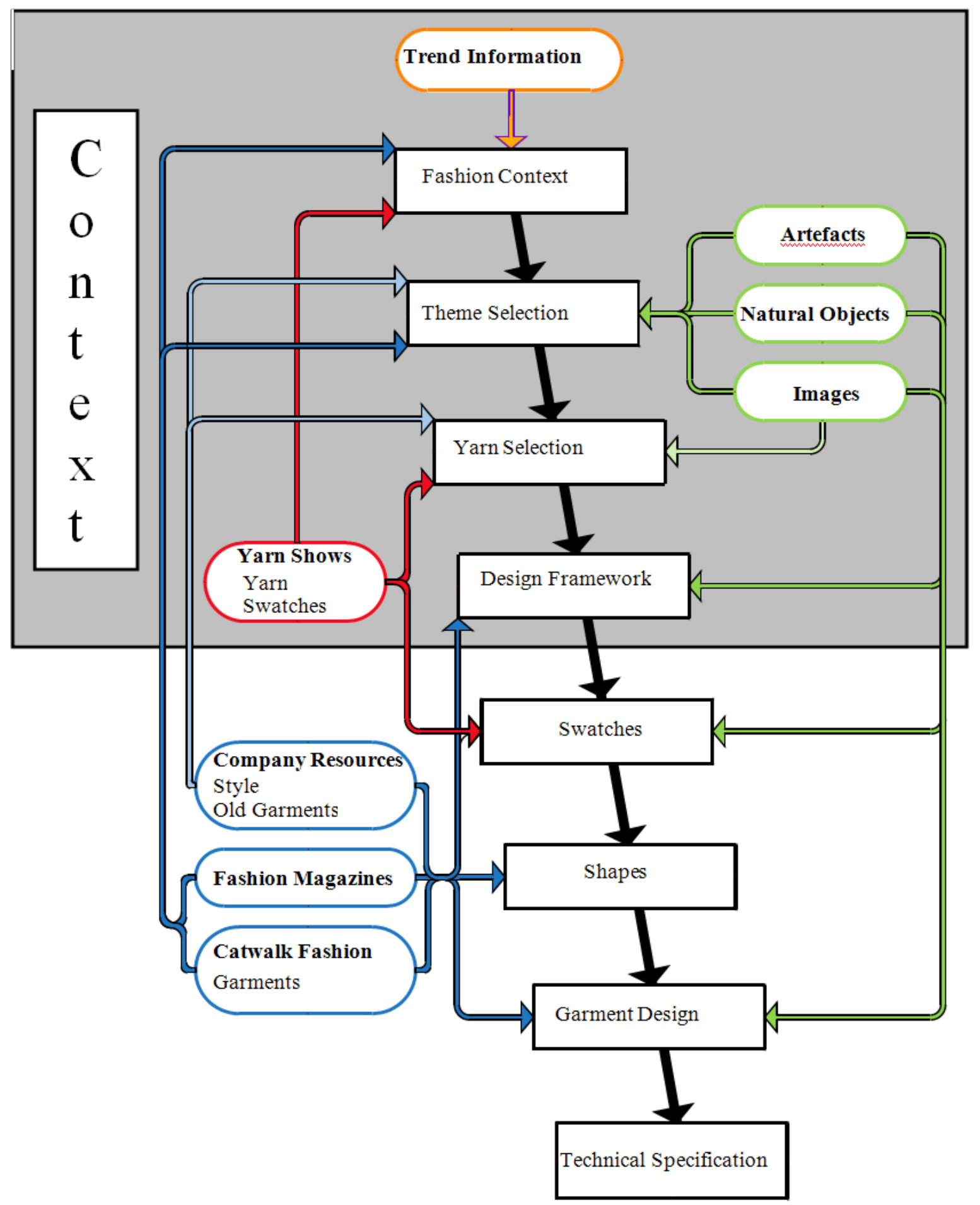

Figure 2 Sources of inspiration in the knitwear design process

However, the influence of garments and other sources of inspiration on what designers create is not limited to the design elements the designers consciously adapt from sources they are aware of. Knitwear designers are typically culturally aware individuals who know about the history of fashion and how it is expected to evolve, and who take an interest in other forms of design, for instance graphic design and packaging. They are conscious of trends and what's new and who are seen as innovative designers. They get bored with styles they perceive as old. These wider concerns influence both their goals 
- the aesthetic effects they want their designs to achieve - and their perceptions of the relationship between the structural properties of designs and the aesthetic effects they achieve and their acceptability within contemporary fashion, and thus how they evaluate their own and other designs. Thus broad movements in style and taste (documented for instance by Dormer, 1993) that influence the actions of designers who are primarily concerned with following each other (see Eckert and Stacey, 2001).

Theme selection. Once the designers have an initial understanding of where the new season is going, they begin to work out their own fashion themes. Typically each company has four or five different themes for each season, that they have identified during their research. Not all themes are suited to knitwear or to a particular market. A theme is typically expressed on a theme board, which comprises a display of pictures on a board, showing objects that the theme is derived from and garments that express it, and sometimes fabric swatches (see Figure 3). The elements of a theme board often incorporate the actual forms and features designers plan to use in their new designs, as well as showing cultural references and expressing a mood to indicate the context of the designs.

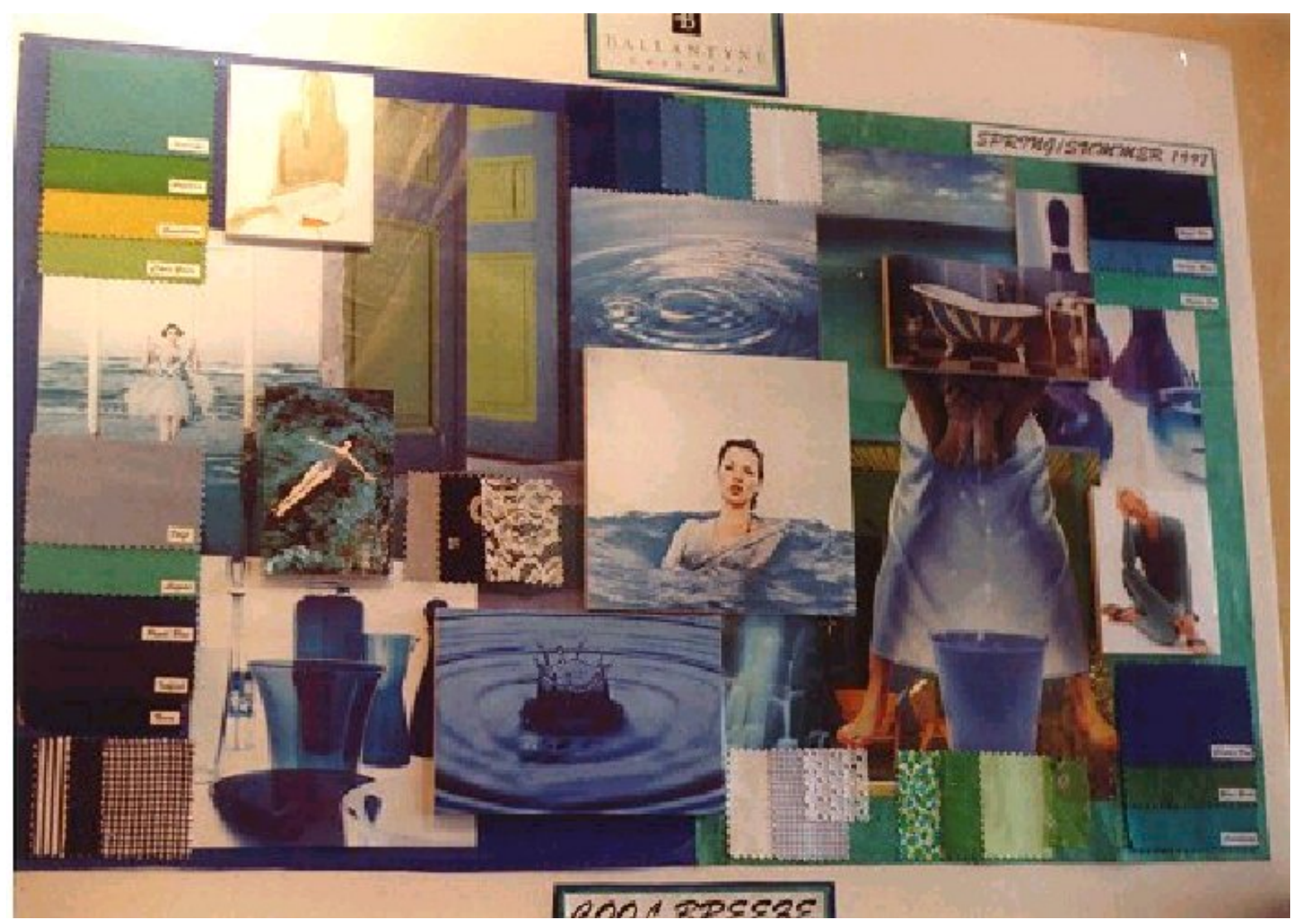

Figure 3 Example of a theme board

Companies who produce their own ranges usually keep a similar balance between the themes; they typically aim for a classical theme, a neutral theme in light natural colours and a high fashion theme. Each company tailors the themes for its needs; high fashion for the teenage market is obviously not the same as for the over 50s market. Other types of themes come from the companies' typical styles. Besides their own fashion research, described above, designers have several sources of information for themes: Forecasting 
materials produced by forecasting bureaux. Upmarket companies have these assembled specifically for them. Other companies buy forecasting books or CDs; and use forecasting magazines. Themes presented in the fashion press, such as Vogue; these are themselves typically derived from the fashion forecasting bureaux' materials. Themes provided by their retailers. Large retailers, such as Marks and Spencer or Next in the United Kingdom, do their own fashion research in the same way as the manufacturing companies as well as looking at what their customers buy and extrapolating trends, and develop their own fashion themes for their entire range. They present these to their suppliers in material largely comprising a series of images that imply moods and cultural connotations as well as suggest design features. If a theme is suitable for their products, companies pick up on it and combine it with the findings of their own research.

Yarn selection. For each theme the designers develop a colour palette of five to seven colours from sources of inspiration related to the selected theme, or by selecting appropriate colours from their customers' colour ranges. For example Marks \& Spencer offers about 40 colours each season to its suppliers. Only the top companies can afford to have yarns developed for them, so that most companies are restricted to the colours pre-selected by the spinners: standard colours and those colours the yarn manufacturers forecast will be fashionable. Images and other objects play an important role in selecting colour ranges. For knitwear the appearance and feel of the yarn is crucial. The texture of the yarn must suit the theme. As far as possible designers try to reuse yarns from past seasons in different colours, because they understand their technical properties. The reuse of yarns is tricky, because the behaviour can vary with the colour. At the same time they try to introduce a small number of new and interesting yarns to keep the selection up-to-date with fashion and introduce interest into their collections.

Design framework. For each theme, a company's designers jointly work out a plan for the types of garments that they want to produce within this theme, in terms of the shapes and pattern elements that they planning to design. Developing the design framework can be seen as the equivalent of conceptual design for knitwear collections. It is not a formal process, but a tacit pulling together of the information that designers have available. The design framework is the first synthesis of what designers have seen during their research with their own style and the needs of their target customers. The final design framework is negotiated between all the designers in a company working on the same season and management or external buyers. It guides the later development of individual designs; however designers are free to develop other ideas which are later included in themes.

The garments proposed in the plan for a range are typically described by short verbal descriptions, such as "Raglan sweater with Arran pattern". Ideas are often expressed and communicated by referring to other designs or to garments the designers know about, as well as through sketches (see Eckert and Stacey, 2000). The whole range is expressed with another theme board, this time including sketches of garments in specific styles.

Designers work out what characteristics the new garments will have, considering what sorts of garments will sell separately and how they can be combined into coherent ranges. They begin by drawing out some ideas that they have, and evaluating them for 
what is missing from what they have seen during their fashion research. The garment designs produced at this stage vary from fleeting ideas to detailed designs; even relatively detailed designs are typically placeholders for categories rather than serious attempts to design individual garments.

Designers make systematic use of sources of inspiration in range planning. They bring sources of inspiration they have collected to meetings, and use them as prompts for discussion of colour schemes and features, and juxtapose them to highlight shared features or aesthetic effects, or illustrate alternative aesthetic effects to be achieved by different garments in a balanced and coordinated range. Range planning can include choosing sources of inspiration for individual designs, to create relatively constrained design problems; common sources are useful for achieving coherence between different designs.

Towards the end of the design process the sample garments are evaluated against the design framework. Slots in the framework that have not yet been filled are then either designed for specifically or abandoned.

Swatch sampling. Swatches are pieces of fabric created independently of any shape designing, that play an important role in the knitwear design process as prototypes in the sense of early versions for testing, and as prototypes in the sense of exemplars that designers draw on for their own designs. Swatches are produced by knitting machine technicians during a large part of the design process. Initial swatches test yarn properties and colour combinations. Swatches are knitted for the design of colour patterns, complex stitch structures, and entire garment pieces. Programs for knitting swatches encapsulate the patterns without the additional programming needed to place them on garment shapes; they can later be embedded in programs for garment pieces. Often designers have quite concrete and detailed ideas for garments in mind when they create swatches, but they often also develop patterns on swatches before considering how to place them on shapes. We discuss the development of swatches for structure patterns and colour patterns in section 4.3. At the end of swatch development all the swatches are evaluated, and the design elements they embody are combined in garment designs. If more swatches are required they are created specifically for individual designs.

Shape design. The shape of the garment is often designed independently of the fabric. Many shapes remain fairly constant with small modifications over the years, especially in menswear and classic ladieswear collections. However, the designers are on a constant look out for shape details, such as necklines and pockets, which as small modification to standard shapes, give the garment a new look. These shape details are mainly derived from garments designers see on their shopping trips or in magazines. Plain fully-fashioned knitwear is reliant on the colour, the material and the shape. At the top end of the fully-fashioned market expensive materials are combined with subtly updated shapes. The inspiration for these shapes is often derived from tailored garments or historical knitwear.

Garment design. Garments are either designed as complete entities or made up from structures and motifs drawn from previously sampled swatches. For the former category the overall inspiration is often taken from garments that the designers have seen and whose overall effect they wish to recreate. Entire garments are often derived 
from sources of inspiration within a topic in the same way as swatches. Large-scale figurative designs especially are almost always derived fairly closely from a figurative source of inspiration. Some garments are entirely based on other garments without the use of any other sources of inspiration. In most of these cases the garments are simplified to meet the companies' price points.

Detailed Design. When the designer is happy with the conceptual design, it is proposed for selection either by the designer alone or by a meeting of the company's team of designers, before the selected designs are carried further into technical development. In knitwear detailed design is coextensive with technical development, which is usually done entirely by the knitting machine technicians. Technicians typically work through a pile of designs, without discussing them with the designers, often in a different building and sometimes in a different country. The knitwear designers produce technical sketches, each comprising a short written description, values for a set of size dimensions, called measurements, and a single freehand sketch. These can be incomplete, inconsistent and ambiguous, as well as vague, so the technicians often have to make design decisions in the course of interpreting them (Eckert, 2001; Stacey, Eckert and McFadzean, 1999; Stacey and Eckert, 2003). Designers sometimes give technicians the source images they have adapted as a guide. The technicians - like designers in all fields - typically use designs that they have generated in the past as a starting point for their interpretation, or relate the specification to basic categories; while the designers' understanding of category labels is influenced by their knowledge of coming fashions. In consequence knitted garments often end up looking rather more similar to previous garments than their designers intended (Eckert, 2001).

The technicians use sophisticated CAD systems to create exact descriptions of the garment pieces as grid patterns of stitches, or in another symbolic representation, from which the knitting machine programs are compiled. (Knitwear designers sometime produce colour pattern designs themselves.) Finding or developing a structural description of a stitch structure to match a designer's sketch involves recognising or imagining analogous forms in a different medium in a way that is very similar to how knitwear designers develop conceptual designs from sources of inspiration (see section 4.3).

A complete knitting machine program is needed before a swatch can be knitted or an accurate computer simulation can be created, to show the true relationship between a knitted structure and the visual effects it creates. There is no accurate model of a complex knitted structure, other than the real thing or a computer simulation of it (Eckert, 2001).

Prototyping. Technicians produce swatches or prototype garments on knitting machines. This is called sampling. Programming the knitting machine, setting it up and washing the fabric in finishing lotion can take easily half a day of technician time for each swatch or prototype knitted. The technicians aim to show the designers finished garments as soon as possible, and then ask the designers to comment. The time delay between the design and sampling of a piece can be so long that the designers have moved on to another season and forgotten what they had originally intended. If the detailed design is then found to be unsatisfactory it will be changed. If time permits, everything will be tried to make a particular idea work out, once it has been approved as a sketch. At this point no changes are made to the initial idea or the choice of source 
of inspiration; however designers may occasionally want to modify details. Once the designer is satisfied, or when time runs out, the range of prototype garments that has been produced is evaluated by the team of designers against the design framework and their understanding of the fashion of the new season, which will now be more precise than when they created the designs. After an internal selection most manufacturers present their ranges to external buyers to obtain orders before going into production.

Communicating with buyers. When designers present prototype garments for internal selection or to external buyers, they often accompany them with sources of inspiration displayed on theme boards. Source images serve to signal moods and cultural connotations, as well as the new garments' relationship to contemporary fashion. Designers are under pressure to show that they know what they are doing, and they cannot easily justify their design decisions in terms of coherent and understandable rationales (see Eckert and Stacey, 2000); theme boards serve as evidence of fashion research.

\subsection{Selecting sources for individual designs}

The major source of variation in the knitwear design process is the design problem itself: the style of garment, the tightness of the specification, and relationship between the specification and the possible sources of inspiration. In knitwear as in other forms of designing such as engineering design by modification, the source can be fixed and therefore implicit. However for much knitwear design the selection of effective sources of inspiration is critical, and is the central creative step. The ability to formulate the right design problems, as needs for garments that will fit into fashion and the company's market niche, in terms that facilitate spotting good sources, is a knitwear designer's most important skill.

Design frameworks: theme or mood. Designers systematically search for relevant garments and fashion images during their fashion research, as well as looking out all the time for objects and images that suggest ideas. Once they have selected a theme or a plan for an individual garment, they tune their source hunting activities to the demands of their design problem. They look for sources that suggest structural elements of designs that have the emergent visual effects and cultural connotations they require. In many cases they don't know what they are looking for until they have found it, but are able to select likely places to find sources from more abstract characterisations of their design problems. They look at source books on particular topics, such as a book on boats for a maritime theme, as well as general pattern books.

Designers' perceptions of objects, their appreciation of their characteristics and recognition of suitable sources of inspiration, are influenced by a subtle understanding of the context of fashion and the requirements their designs must meet (see Eckert and Stacey, 2001). However, designers don't all see the potential of sources in the same way, and some have idiosyncratic strategies for finding sources. For example a designer explained to the first author that when she needs an interesting shape she usually looks at the shapes between relief elements in a book on antique sculpture. Designers' creativity often lies in their ability to see how a design element can be used in a new context. 
Searching for non-garment sources is important when colour patterns and other motif elements are fashionable; when shape is critical the key sources are other garments which designers are aware of during their fashion research.

Opportunistic source selection. Searches differ in how tightly they are driven by immediate needs, and how much they are opportunistic with needs latent - for all the garments within the design framework, or for fashionable garments for a season. Very often systematic searches for inspirations to meet particular needs yield sources that designers can see how to use in fashionable garments, though not for their immediate problem. Sometimes these are garments within the design framework. Sometimes designers pursue design ideas even though they are outside the company's plans. If a designer likes a design and feels strongly about it, she can sometimes push it through sampling even if it falls outside a theme or a price point.

Serendipitous visualisation from source. In some cases designers comment that they come across a certain source of inspiration, an artefact, an image or a garment; and they can see it instantly as a complete knitted garment. (Of course, how much detail is in a mental representation that designers experience subjectively as a 'complete garment' is not obvious; see Eckert and Stacey, 2001, 2003.)

Source-specific design briefs. Designers are often confronted with the need to employ a predetermined source. When companies create design frameworks they may choose sources for later adaptation; however these can be abandoned if they fail to produce satisfactory designs. Many companies produce garments to very specific external briefs imposing very tight constraints on the designs. These may specify a source; in particular a lot of childrenswear employs licenced characters, for which designers need to create very faithful translations of sources in another medium.

Precedent designs. Many designs are based on similar garments. Buyers for retailers often specify garments or ranges that they would like to see followed closely. These are garments that they think their target customers would aspire to wear, but can't afford. Buyers are often very reluctant to order innovative designs, unless they can see very similar garments produced by direct competitors or higher status companies. Designers also look out for designs on the market that suit their design specifications. This direct imitation has parallels with architects' use of a canon of precedent buildings designed by a small group of superstar architects (see Clark and Pause, 1985; see Oxman and Oxman, 1992; Goldschmidt, 1998, for discussions of precedents in design thinking). However in knitwear, precedent designs gain normative force not from the status of their designers, but from the aspirations the customers are perceived to have. Thus designers imitate designs of slightly higher status, rather than the designs of famous couturiers.

\subsection{Using sources in individual designs}

As we illustrate in Figure 4, the process of adapting a source of inspiration into an individual design can begin in one of two ways. (A) The brief specifies a source implicitly or explicitly, or the designer encounters a source that she likes. (B) The designer starts with a more abstract idea for a design, and then selects a source of inspiration that fits this idea and can be used to express it. 
The source is adapted into a visual representation of a knitted structure. This may take the form of a sketch, or it may only be a mental model in the designer's head; several designers have commented explicitly that they often design entirely in their heads until they are ready to draw pictures to communicate their ideas to others. This representation includes the emergent visual properties the design should incorporate, and identifies categories of structural elements, but typically not the detailed structural features of the stitch structure or the whole garment that will produce those visual properties. The features of the source are modified to conform to the constraints imposed by the medium and include matching structural elements such as cables. This involves constructing an analogical mapping between elements of the source and possible knitted design elements. Although the mapping is based on surface perceptual similarity, this has some parallels to creative design by analogy in engineering, architecture and other fields (see A. Goel, 1997), which depends on recognising the correspondences between sets of structural relationships in two domains (see Gentner, 1983). Gentner and Markman $(1995,1997)$ note that the recognition of perceptual similarity appears to involve processes closely related to analogical thinking.

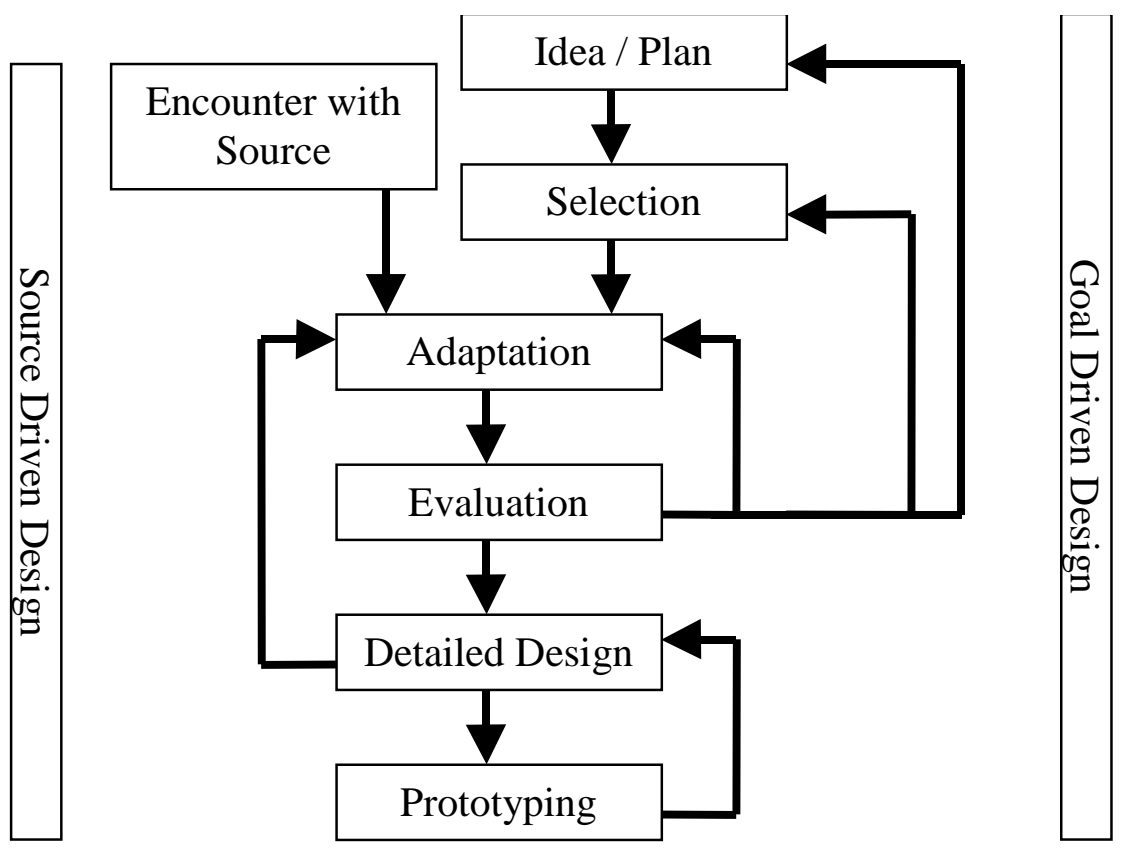

Figure 4 The process of adapting a source of inspiration into a design

The adaptation is evaluated. If the designer is not happy, she might change the adaptation or choose a new source, or conclude that the original idea for the garment will not work and abandon it. At this stage the evaluation of a design is entirely perceptual and tacit. When asked how they know whether a design looks right, designers typically respond "I just know". As we remarked above, during the fashion research stage designers fine tune their tacit perception of the envelope of designs that are legitimate within a particular fashion. They evaluate new designs against this envelope. In addition they apply their general sense of balance, proportion and colour, to appreciate the properties of the design, including its cultural connotations. This early evaluation process is not subject to observation, because designers typically only express whether they like something or not, but do not comment on why they like something. (Features or faults of balance or proportion are not easy to express in words, nor are subtle relationships to other garments.) Design decisions are rarely 
explained in rational terms, but are justified by the strength of subjective belief (see Eckert and Stacey, 2000).

A particular design can go through this process several times at different levels of detail. The initial overall idea of the design can be inspired by one source of inspiration and the details can be worked out using other sources of inspiration. This two step process often occurs when a designer is creating a new version of a more upmarket garment, where the overall design is based on this garment, but the details are derived from another source. The timescale of the adaptation process varies. If the design is developed purely as a mental image then the entire process can only take seconds, as designers often comment. Other designs require much longer, when the adaptation is worked out in detail. For example the translation of a swirly design into a grid pattern can take several hours even with the support of modern CAD systems.

Sources of inspiration are handled differently for the three aspects of detail design that they inform: Knitwear designers normally sketch out shape features without working out how they will be implemented in detail, or visualise shape features in use by visualising a new design. Their mental and paper representations of shapes leave out the levels of detail at which technical problems arise; they leave these to their technicians. Structural aspects of these features need to be altered from previous exemplars to fit their new contexts, or recreated from more abstract and cryptic representations, but without any need to map by analogy into a different set of structural terms.

Most knitwear designers find it very hard to create structure patterns, such as complicated cables or lace patterns, from scratch or from not-knitted sources. The source of inspiration reminds the designer of a structure pattern that could be used, for example some tree bark might remind a designer of a certain tuck stitch pattern. Even though themes with structure patterns are often expressed through images, for instance of architectural details or Celtic artwork, structure patterns are rarely derived directly from images. This is because the angles of the lines that can be generated in knitted fabric are restricted by its form as rows and columns of large discrete stitches. An alternative way that designers work is by sketching the appearance that they want to achieve through a structure pattern, and asking their technicians to produce that result. Designers' desires vary in how closely the technicians need to create what's asked for, as opposed to achieve emergent aesthetic effects; this is a cause of confusion and conflict (see Eckert, 2001).

Structure patterns are typically created by modifying existing patterns in other swatches, garments or pattern books, to capture the visual characteristics of the source of the design idea. Reverse engineering a complex stitch structure from a piece of fabric can be difficult and time consuming. Modifying a program is easier, therefore companies often use their own old swatches, or swatches developed by knitting machine manufacturers to show the scope of their machinery. So many new swatches are knitted as modifications of existing swatches. Knitwear companies often keep sample garments, but very few keep swatches. They usually don't generate or keep any paper description of stitch structures nor do they keep their sketches. Lack of record keeping is also a problem in other parts of the textile industry (Scaife, Curtis and Hill, 1994). Only very few companies have the time and technical expertise to develop novel structure patterns, which are later widely copied throughout the industry. Many innovative stitch 
structures come from students; and we have encountered a small business that creates swatches of colour patterns to sell at yarn shows.

Most designers develop their own colour patterns, unless they are copying existing garments or using traditional patterns. Colour patterns are adapted by selecting the entire source or parts of it and mapping it onto a grid pattern. Only simple geometric patterns are normally created without using a source of inspiration. Some designers make initial sketches; others go straight to a CAD system to draw a grid pattern. Motifs are often used in knitted patterns with the minimum possible amount of modification, but as knitwear has a low resolution (a single stitch is quite large) and a limited set of colours, almost all colour pattern sources require radical simplification. Creating a gridded pattern from a finer-resolution image is not a mechanical process. The results depend on who does it. Knitwear designers seem not to be very conscious of this and often delegate creating gridded patterns to their technicians. By contrast, carpet designers, who also create gridded patterns from finer-resolution sources, are very well aware of how subjective and variable this is (Adrian Demaid, personal communication, 1996).

We have reported elsewhere (Eckert and Stacey, 2003) on an experiment run with nine professional knitwear designers and eleven knitwear design students with a year's industrial experience, who were asked to design sweaters given a design brief and an image to use as a source of inspiration. We used two sources: one was a Persian carpet, and the other was a swirly flowery Nineteenth Century tapestry pattern. While this was an entirely realistic activity, designers in real life would normally be free to reject sources that didn't suggest designs. We found that our subjects followed a variety of strategies in adapting the sources. There was a fundamental division between two main approaches: where the visual elements in the source itself suggested the form of the design; and where the selection and adaptation of elements of the source was guided by a more abstract plan. The designs that were driven by the source varied in the degree of abstraction and the fraction of the source that was used. The most frequent strategy employed was to use the most salient feature of the source in the new design, in a similar form and position within the design. Other strategies employed features that the designers liked. Some designers tried to capture the overall impression of the source by creating designs that shared more abstract characteristics; for example two of the most experienced designers tried to recreate the intertwinedness of the leaves in the tapestry pattern though cable patterns in natural colours.

\subsection{Commonalities and differences across the industry}

We have observed sources of inspiration being used in the same way in all the companies we have seen, from the suppliers of cheap mail order houses to the world's leading design companies. Only a very few knitwear companies in the world, such as Missoni, set the trends by defining their own themes rather than following the themes suggested by others. In all cases the designers study the development of fashion primarily by looking at other designers' garments at shows, in magazines and in shops (see Eckert and Stacey, 2001), and gather source material within themes and adapt it into designs. Eckert (1997b) described the knitwear design process with a detailed flowchart model of individual activities and their possible sequences, much more finegrained than the outline shown in figure 2; she found that while all the companies she 
studied fitted this flowchart, they differed in how much effort they put into particular activities and in how much backtracking they allowed. The more upmarket companies invest more money in the design process, and designers have better opportunities to do research. These companies give the designers more funds to travel to shows and shop further afield. Some companies, regardless of their place in the market, have collections of inspiration books. In almost all companies the designers complain about the lack of suitable inspirational material provided by the companies; most designers pay for design resources out of their own pockets and devote much of their 'free time' to looking for potential sources of inspiration.

Some of the more upmarket companies have dedicated sampling machines, which enable designers to obtain design swatches and sample garments as and when they want them, rather than having to fit round production schedules - this makes a major difference to the form of the design process. They are better able to revise garment designs repeatedly after they are sampled, and invest more resources in getting individual designs right, so they are better able to avoid making compromises for ease of technical implementation, and can make more daring use of novel yarns whose technical properties are not well understood.

As we observed in section 3, imitating other people's designs is prevalent throughout the industry, especially to produce cheaper versions by using different yarns or reducing the complexity of the knitting operations. Elements of other designs are routinely used to specify new designs, because specifying stitch structures is extremely difficult in the absence of an example that can be copied or modified (see Eckert and Stacey, 2000).

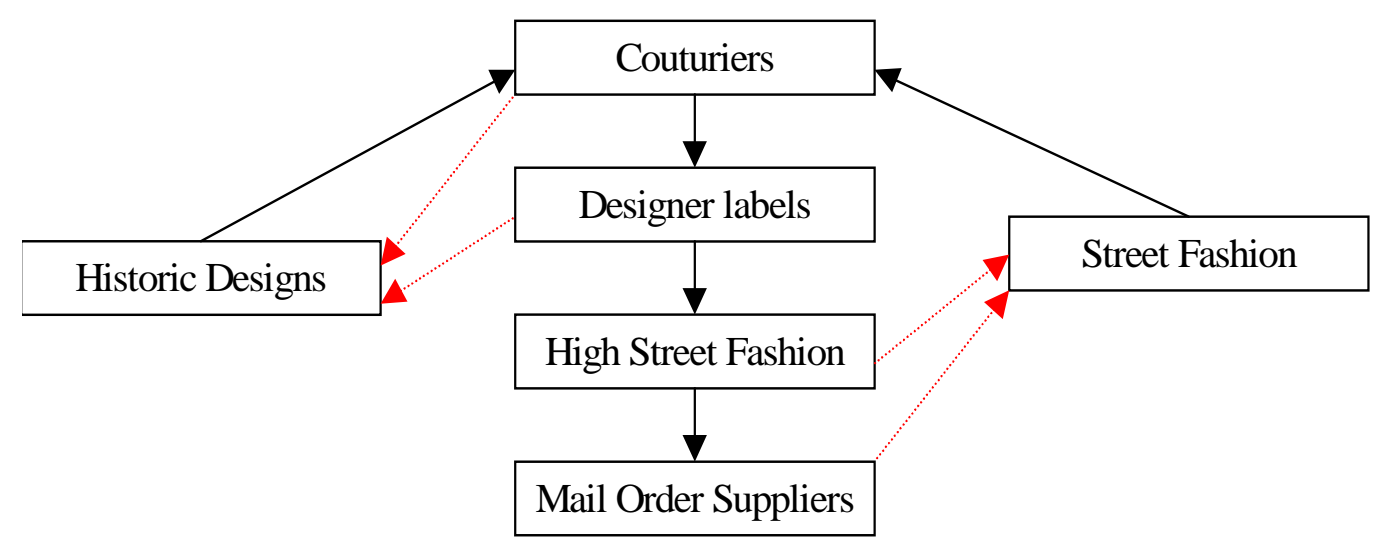

Figure 5 Imitation hierarchy in fashion industries

Figure 5 illustrates the imitation hierarchy in the textile industry. The solid arrows should be read as "inspire", the dotted arrows as "become over time". Each box can be seen as a distinct level in a fashion hierarchy. The couturiers develop their own themes and fellow global trends and moods. They do not, however, follow trends identified by forecasters. Couturiers set trends for others to follow. Many couturiers, for example Vivienne Westwood or John Galliano, draw their inspiration from historic designs, others are inspired by street fashion. All designers draw inspiration from what they see people wearing. Street fashion can mean the clothes that people wear; but the term is used more precisely for emerging fashions which combine not particularly fashionable ordinary clothes with the influences of subcultures; the classical examples are the punk 
fashion of the 1970s, and the mods of the 1950, who drew inspiration from Edwardian clothes. Of course the relationship between such subcultures and the fashion industry can be subtle. According to McDermott (1999) punk style was essentially invented by Malcolm McLaren and Vivienne Westwood, an extremely historically aware high fashion designer - they were themselves influenced by the New York punk bands Richard Hell And The Voidoids and the Ramones. Designer label companies pick up on the trends set by the couturiers and themes suggested by the trend forecasters; they interpret the new themes introduced by the couturiers into wearable fashion. They draw on historic sources for individual garments and details, but would not use them to introduce completely new looks; they ignore street fashion unless it is a strong theme in its own right. High street fashion takes designer label fashion into the mass market. High street retailers select styles that are suitable to a wider range of price points and customer groups. At the cheaper end of the market, for instance for suppliers to supermarkets, designs are mainly inspired by more upmarket high street fashion. Many of these designs are cheaper simplified versions of high street designs. High street fashion and the cheaper clothes become street fashion, which in turn inspires the couturiers. Garments produced at each level in this hierarchy directly influence garments one level down, but don't have a direct influence on garments further down the chain.

Fashionable features appear earlier in the shops in garments from companies higher up the imitation hierarchy, influencing how designers lower down the hierarchy perceive the range of possibilities open to them within the current fashion (see Eckert and Stacey, 2001).

The variations in the pattern of design activities and design thinking that we observed did not depend on the individual designers. All the designers we observed and interviewed explained the process in similar terms. All the designers commented on using the same type of inspiration materials. Variations occur at the level of individual designs, according to what the sources of inspiration are and what the constraints are on the required design. While most designs are based on a design framework or a buyer's brief, the starting point for each particular design is different. Individual garment designs are created at different point in the overall design process, and under slightly different constraints. Some designs are the product of early design development, which the designers could work out conceptual designs in detail, because they had time. However these might have to be altered later to tweak them towards new developments in fashion. Other designs are created under great time pressure to meet fairly close specifications, for example when the collection is evaluated against the design framework and certain slots still need to be filled to a deadline. Some designs are created under strong pressure to meet very tight cost restrictions. Each designer in each company we observed encountered most of the same types of design problem, and adopted the same design strategies to deal with them.

\section{Patterns of idea generation}

In studying engineering design processes (see for instance Eckert, Clarkson and Zanker, 2004), our experience with knitwear design has enabled us to generate hypotheses and ask questions about issues and problems that are important but are much less visible in engineering than they are in the knitwear industry. In this section we systematise and generalise the insights we have gained into how knitwear designers use sources of inspiration, to facilitate hypothesis-driven comparisons with other industries. 


\subsection{Strategies for idea generation}

Acts of creative imagination are not fully controllable or predictable. Nor do we have any way to describe designers' mental pattern synthesis actions that does justice to their richness and complexity. But we have found that we can nonetheless make sense of knitwear designers' activities as rational goal-directed problem solving behaviour directed to creating new designs. A designer's pattern synthesis actions are tuned to the demands of the task, and are influenced by the concepts and experiences in the designer's memories (Oxman, 1990; see Eckert and Stacey, 2001) - most importantly the aspects of the design problem that the designer has most recently considered (Darke, 1979), but also other recent experiences, especially other similar designs (Jansson and Smith, 1991; Purcell and Gero, 1996). We have seen that knitwear designers apply conscious and systematic strategies (though they wouldn't describe them in quite these terms) for providing themselves with the appropriate sets of experiences in memory to enable them to imagine new design ideas of the sort they want, as well as to evaluate their ideas. We have also seen that knitwear designers apply a variety of procedures for formulating design problems so that they could use particular experiences and elements of the environment - sources of inspiration - to create parts of designs (Eckert and Stacey, 2003).

Designers' creative thinking, in which pattern synthesis actions are embedded, can appear chaotic but is usually highly structured. As Visser $(1990,1994)$ and others have observed, designers including engineers and software developers are guided by global plans but act opportunistically to correct mistakes, respond to unexpected events and fulfil latent goals. Such situation-driven contingent behaviour, using goals and plans as resources, is characteristic of all human thinking (see Clancey, 1997; Suchman 1987). Visser (1992) has shown that designing behaviour can effectively be described as the application of knowledge at the levels of plans and organisation, strategies, and problem solving processes, and has observed a directed search for analogies from which elements of designs could be adapted.

It is probably infeasible to create detailed content-specific models of what happens in the creative flash (as opposed to theories of the cognitive mechanisms involved). However Smithers $(1996,1998)$ has argued that designing can most fruitfully be modelled at the knowledge level, describing what it is that designers need to know in order to create designs; we have argued elsewhere that ethnographic observation can provide the data for knowledge level modelling of design expertise and design processes (Stacey and Eckert, 1999). Our observations reported here support the conclusion that we can seek to understand creative thinking by understanding the problem solving knowledge designers apply to guide idea generation by providing themselves with useful memories and formulating soluble problems.

\subsection{Setting goals and using sources of inspiration}

In knitwear design we have seen designers using sources of inspiration driven by a variety of goals; moreover these goals change in the course of developing the designs. We have also seen the use of sources of inspiration differ according to the situation designers find themselves in, both between designs and within a single design. What governs this relationship? The differences lie in how designers formulate their goals in 
searching for and adapting sources. Here we place these goals on a set of dimensions, and trace the path of the design process through the space these dimensions define.

Abstraction. When looking for and looking at sources of inspiration, designers can conceptualise what they want differently. In terms of the structure of the design structural characteristics of the design elements they want to find, and the relationships they should have with other elements. (In knitwear, these are shape, angles and relative sizes, colour contrasts, and so on). Or much more abstractly in terms of functions and emergent behaviour including aesthetics (in knitwear, projecting cuteness, severity, elegance, or whatever, and fitting into a theme and taking a position in the envelope of fashion). In knitwear design a frequent goal at an intermediate level of abstraction is to create garments belonging to the same categories as particular other garments and sharing the same emergent aesthetic effects. Designers with functional or aesthetic goals need to find ways to restrict the scope of their problem and give themselves more concrete and exact structural goals. This will be achieved by a source of inspiration that suggests appropriate goals in structural terms to create a design that fulfils the abstract goals. Although degree of abstraction is a continuum, we can usefully distinguish between design behaviour driven by structural goals, and design behaviour to find structural goals.

Tightness of constraints. Design situations differ in how tightly they are constrained by the requirements the design must meet and the other elements of the design into which the new element must fit, and thus how exactly the space of acceptable designs is defined. In knitwear design this continuum divides into two categories of goals: to define the space of desirable designs within which an acceptable individual design should fit; and to create such an individual design.

\section{Plan emerges $\quad$ Plan driven}

\begin{tabular}{l|l}
$\begin{array}{l}\text { Unstructured } \\
\text { fashion research } \\
\text { (tuning tacit } \\
\text { understanding) }\end{array}$ & Theme definition \\
\hline \multicolumn{1}{|c|}{$\begin{array}{l}\text { Design Framework } \\
\begin{array}{l}\text { Source-driven design } \\
\text { with aesthetic or } \\
\text { functional objectives }\end{array}\end{array}$} & $\begin{array}{l}\text { Plan-driven } \\
\text { conceptual design }\end{array}$ \\
& Detailed design
\end{tabular}

Figure 6 Space of goals for adapting sources of inspiration

Scale. All but the simplest design problems involve making choices at different scales. In knitwear decisions must be made about ranges of garments, as well as individual garments, the choice of motifs and structural elements and their relationships with each other, and the internal details of particular design elements. In knitwear design any source can be employed at any of these levels - or more than one as we have observed. 
But as time progresses and the focus of designing activities moves to smaller scales becoming more concrete and constrained, sources are less likely to influence designers' thinking about larger scales - they need to be really striking to make an impact.

Figure 6 shows the space defined by the abstraction and constrainedness dimensions, divided into four regions by our two basic distinctions. In the upper left corner - where goals for design space definition emerge from looking at sources, guided by more abstract or general goals - is unstructured fashion research. In the upper right corner where goals for design space definition are formulated partly in structural terms - is theme selection. In the lower left corner - where abstract or aesthetic goals for creating individual designs guide the generation of more precise subgoals in structural terms are source-driven design strategies, where the characteristics of some source trigger ideas for designs. In the lower right corner - where the development of individual designs is directed by structural goals - are plan-driven conceptual design strategies and detailed design.

In knitwear as in other industries, progress in design consists in defining the problem and the design in progressively more detail, with a correspondingly tighter definition of further design goals. But this progress towards more concrete, operational and exact goals often isn't monotonic along all dimensions. As Figure 7 illustrates, design thinking in knitwear often follows a $\mathrm{Z}$ path, with thinking in structural terms about less constrained, higher level problems followed by more open-ended thinking about more detailed and tightly constrained local problems, which may be in more abstract and functional terms. This often involves trawling for sources of inspiration likely to trigger the imagining of design elements for the more local problems.

\section{Plan emerges $\quad$ Plan driven}

\begin{tabular}{l|l}
$\begin{array}{l}\text { Unstructured } \\
\text { fashion research } \\
\text { (tuning tacit } \\
\text { understanding) }\end{array}$ & Theme definition \\
\hline &
\end{tabular}

Figure 7 Path of the design process through the space of goals

As some constraints tighten others must be relaxed - sometimes including designers' assumptions about how to solve a problem. In engineering often the most creative designing is manoeuvring round conflicting hard constraints in designing details, so for complex systems the design process can have a recursive structure. Similarly the challenges in knitting machine programming come in devising ways to achieve particular aesthetic effects given the complexities of knitted structures, yarn properties 
and the costs of knitting machine operations. In knitwear, the sources that are employed in fashion research and theme selection need to be contemporary and fit into themes. The selection of sources to solve smaller-scale, more tightly constrained problems in designing individual garments can be much freer, especially for designing details.

\subsection{Evolution and adaptation in designing}

It has long been recognised that design thinking is characterised by a cyclic process of reformulating the problem, generating a move in the space of possible candidate designs, evaluating the design, reformulating the problem again, and so on (Asimow, 1962; Hillier, Musgrove and O’Sullivan, 1972; Darke, 1979; see Cross, 2000). When we can solve a design problem by applying a sound method for deducing a solution from the problem statement, we no longer think of what we do as designing. But this formulation focuses attention on the undeniably important process of developing a 'single' design by iterative evolution. In this section we outline an expansion of this traditional cyclic view that gives due importance to the selection and adaptation of external sources of ideas.

The most detailed research on the creative process in design has examined the evolution of ideas, and has used videotapes of episodes of designing in artificial experimental situations. Most of this work has studied architects, and much of it has focused on how designers use sketching (see Purcell and Gero, 1998, for a review), with notable contributions coming from Schön (1983), Goldschmidt $(1991,1994)$ and V. Goel (1995). It has described how ideas emerge from designers' reflection about their own sketches. The vagueness and ambiguity that makes sketches problematic for communication (Stacey, Eckert and McFadzean, 1999, Stacey and Eckert, 2003) facilitates reinterpretation driven by dissatisfaction with the current design (McFadzean, Cross and Johnson, 1999). While this work rightly highlights the role designers' perceptions of external representations of their own designs play in the cycle of design thinking, it is limited by its experimental paradigm. (This is not to suggest the researchers are so limited: for instance Schön (1988) discusses architects' recollection of functional types and references; and Goldschmidt $(1995,1998)$ has written about the roles of precedents and references in architecture.) Designers are told to design and if possible concurrently verbalise for a given (short) time outside their normal work environment. In these experiments external sources only play a role in so far as the designer can recall them during the design activity. In most normal design situations, designers are free to refer to inspiration objects, and think about their designs outside their offices; they would often actively research solutions to similar problems. As we have found in our observational and experimental work (Eckert and Stacey, 2003), knitwear designers interact with sources of inspiration in very similar ways to how Schön and Goldschmidt's architects interacted with their sketches.

In combination, the sources and the designers' current formulation of the design problem trigger the generation of new design elements that are adaptations of the sources. As we have just noted, a lot of designing comprises the iterative evolutionary development of a 'single' new design. It is stretching a point to call the current version of a new design a source of inspiration, but there is a close parallel between the way new design ideas are triggered by considering external sources of inspiration and the 
way they are triggered by considering the current design. Considering these two processes as the same is a fruitful perspective on design thinking.

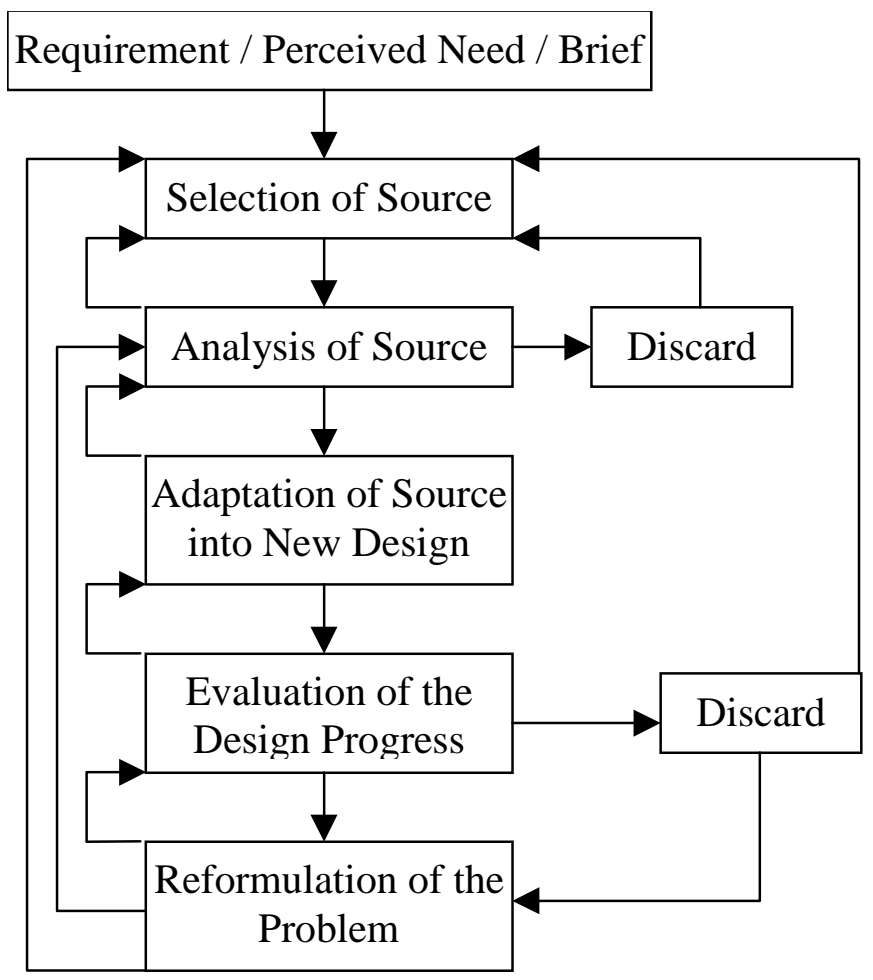

Figure 8 Design cycle involving sources of inspiration

The flowchart in Figure 8 describes the creation of a new design based on a source of inspiration, as a cyclic process. It asserts that movement down the chart from selection of the source of inspiration to reformulation of the problem happens in the sequence of stages shown here. However movement up the chart to earlier points in the cycle can happen in a variety of ways, according to when and how designers perceive inadequacies in what they have done so far. This view subsumes the more traditional view of the design cycle - and assimilates our observations of design practice to the traditional cyclic view - by equating adapting previous designs and drawing on external sources of inspiration with modifying the existing design solely with reference to itself. It highlights the selection of sources of inspiration as an essential factor in design thinking; in some situations the choice is fixed and therefore implicit, in other situations this is the critical activity.

Confronted with a new design task, the designer looks for a starting point in the form of an old design or an external source of inspiration, if this is not predetermined. Each source is analysed and evaluated for its suitability, and discarded if it does not fulfil the need. The analysis can involve nothing more then a fleeting glance at a picture in a book, but might be a detailed investigation of the capabilities and characteristics of a complex product like a machine. For some designs the selection - analysis loop can be repeated many times until a suitable source has been found or enough sources identified. The source, or parts or aspects of it, is then adapted by modifying, adding, or subtracting elements of it, or translating it into a different form that fits the new problem context. This process is conventionally seen as the main design activity. The new design is evaluated as it is created or after it is finished. Sometime the design is discarded either 
because the adaptation itself is unsuccessful and needs to be repeated, or because the result fails to meet expectations. In this case the designer returns to the source to create an alternative adaptation, or finds a new source. As the design progresses each evaluation of the current state leads to some reformulation of the problem. The most radical reformulations of the problem become necessary when the design has failed and the designer realises that a fresh look at the problem is required.

In evolutionary design, the current version of the design is the main source of inspiration. Its features, intended or unintended, expected or unexpected, are analysed or directly perceived (what Schön and Wiggins, 1992, term appreciated) by the designer, just as the designer appreciates the characteristics of another object. The major differences are firstly that early designs are incomplete, provisional, often ambiguous and sometimes self-contradictory, while typical sources are complete and therefore fixed; and secondly that ones own designs cannot be divorced from their intentions, while the intentions motivating the design of external sources are at most implicit. The move in the space of possible designs at the heart of the cycle might be a wholistic synthesis or transformation of a design, but is more typically an incremental modification to part of it. When an external source is used in incrementally developing a design, evaluations of both the source and the design contribute to the perceptions of the design task that trigger design steps.

Of course, complex design processes are only tractable because they are hierarchical, both in space and time. Design tasks are decomposed as far as possible into almostindependent subproblems (Simon, 1996), and designing complex artefacts often consists of nested loops going through this cycle on timescales ranging from seconds to days. In some industries specialists are employed to perform particular types of evaluations. Thus the problem reformulation step in the cycle may involve a transition to a new problem space to address a subgoal, either in pursuit of a plan or opportunistically in response to a perceived problem, or a return to a previous goal on completion of a subgoal.

\section{Conclusions}

Knitwear designers make extensive, explicit and systematic use of sources of inspiration throughout their designing activities, to understand the scope of fashion, in planning their design work, and in the design of individual garments. Compared with designers in other industries, knitwear designers are very aware and open about their adaptations, very broad in their choice of sources, and very specific and concrete in the ways they think about them. Knitwear designers' use of sources of inspiration differs remarkably little between companies and individuals; the variation is between individual designs.

In knitwear design, finding and choosing appropriate sources of inspiration is a crucial part of the creative process. A knitwear designer's most essential skills are, first, using other garments and other sources of inspiration to tune perceptual evaluations of designs; and second, choosing effective sources to adapt. In many cases the process of actually transforming a source of inspiration into a design is a much less significant part of creating the new design.

We have found that it is possible to study creative design thinking by examining the strategies designers use to guide and control their idea generation actions so that they 
produce the kinds of results the designers need. Strategies for finding sources of inspiration, both for formulating design problems and for adaptation into individual designs that meet the designers' requirements and constraints, are an important part of knitwear designers' knowledge. Designers' strategic knowledge includes ways to formulate different types of goals for source searches; these change systematically in the course of designing for each season (section 5.2). We have described elsewhere how the world's fashion and knitwear designers collectively generate fashion by applying essentially similar strategies for finding and selecting sources of inspiration (Eckert and Stacey, 2001).

The vital importance of selecting appropriate and effective sources of ideas to adapt has been neglected in many discussions of design thinking, despite the extensive research on sources of ideas and adaptive design in architecture, engineering and other industries. We present a revision of the classical cyclic view of design - reformulate the problem, change the design, evaluate the change, reformulate the problem - that gives due importance to source selection (section 5.3).

A further conclusion we have drawn before (Eckert, 1997a; Eckert and Stacey, 1998) from our research is that designers in knitwear and other industries need active management support and encouragement in renewing their stock of potentially fruitful experiences, and in finding sources of inspiration. For knitwear designers this can be done by supporting visits to exhibitions and trade shows; and by providing stocks of potential sources such as books on art and ornamental design.

\section{Acknowledgements}

Claudia Eckert's research on knitwear design was supported by grant GR/J40331 from the ACME initiative of the SERC, grant L12730100173 from the ESRC for the MIND project, and grant 717 from the Open University Research Development Fund. Her research has also been supported by the EPSRC block grants to the Cambridge Engineering Design Centre. We are very grateful to all our informants for the time and trouble they took talking to us; this research has especially benefited from many conversations with Monica Jandrisits.

\section{References}

Agar, M. (1980) The Professional Stranger: An Informal Introduction to Ethnography. Academic Press, London.

Atkinson, P. and Hammersley, M. (1994). Ethnography and Participant Observation. In Handbook of Qualitative Research eds N.K. Denzin and Y.S. Lincoln. Sage, Thousand Oaks, CA.

Asimow, M. (1962) Introduction to Design. Prentice-Hall, Englewood Cliffs, NJ. Clancey, W.J. (1997) Situated Cognition. Cambridge University Press, Cambridge, UK. Clark, R.H. and Pause, M. (1985) Precedents in Architecture. Van Nostrand Reinhold, New York.

Cross, N.G. (2000) Engineering Design Methods, 3rd edition. John Wiley, Chichester, UK.

Darke, J. (1979) The Primary Generator and the Design Process. Design Studies, 1, 3644. Reprinted in Developments in Design Methodology ed N.G. Cross, pp. 175-188. John Wiley, Chichester, UK. 
Dickson, K. and Coles, A.-M. (1998) Design protection and copyright issues for small textile firms. Design Studies, 19, 203-215.

Dormer, P. (1993) Design since 1945. Thames and Hudson, London.

Eckert, C.M. (1997a) Design Inspiration and Design Performance. Proceedings of the 78 $8^{\text {th }}$ World Conference of the Textile Institute, vol 1, pp. 369-387. The Textile Institute, Thessaloniki, Greece.

Eckert, C.M. (1997b) Intelligent Support for Knitwear Design. PhD thesis, Department of Design and Innovation, The Open University.

Eckert, C.M. (2001) The Communication Bottleneck in Knitwear Design: Analysis and Computing Solutions. Computer Supported Cooperative Work, 10, 29-74.

Eckert, C.M. and Bez, H.E. (2000) A Garment Design System Using Constrained Bézier Curves. International Journal of Clothing Science and Technology, 12, 134-143.

Eckert, C.M., Cross, N.G. and Johnson J.H. (2000) Intelligent support for communication in design teams: garment shape specifications in the knitwear industry. Design Studies, 21, 99-112.

Eckert, C.M. and Demaid, A. (2001) Classifying Design and Design Management in Seasonal Industries, International Journal of Innovation Management, 5, 401-425.

Eckert, C.M. and Stacey, M.K. (1994). CAD Systems and the Division of Labour in Knitwear Design. Women, Work and Computerization: Breaking Old Boundaries Building New Forms eds A. Adams, J. Emms, E. Green and J. Owen, pp. 409-422. North-Holland, Amsterdam.

Eckert, C.M. and Stacey, M.K. (1998) Fortune Favours Only The Prepared Mind: Why Sources of Inspiration are Essential for Continuing Creativity. Creativity and Innovation Management, 7, 9-16.

Eckert, C.M. and Stacey, M.K. (2000) Sources of inspiration: a language of design. Design Studies, 21, 523-538.

Eckert, C.M. and Stacey, M.K. (2001) Designing in the Context of Fashion - Designing the Fashion Context. Designing in Context: Proceedings of the 5th Design Thinking Research Symposium, pp. 113-129. Delft University Press, Delft, Netherlands.

Eckert, C.M. and Stacey, M.K. (2003) Adaptation of Sources of Inspiration in Knitwear Design. Creativity Research Journal.

Eckert, C.M., Clarkson, P.J. \& Zanker, W. (2004). Change and Customisation in Complex Engineering Domains. Research in Engineering Design, 15, 1-21.

Gentner, D. (1983) Structure-mapping: A theoretical framework for analogy. Cognitive Science, 7, 155-170.

Gentner, D. and Markman, A.B. (1995) Similarity is like analogy. Similarity ed C. Cacciari, pp. 111-148. BREPOLS, Brussels.

Gentner, D. and Markman, A.B. (1997) Structure Mapping in Analogy and Similarity. American Psychologist, 52, 45-56.

Goel, A.K. (1997) Design, Analogy, and Creativity. IEEE Expert, 12(3), 62-70.

Goel, V. (1995) Sketches of Thought. MIT Press, Cambridge MA.

Goldschmidt, G. (1991) The dialectics of sketching. Creativity Research Journal, 4, 123143.

Goldschmidt, G. (1994) On visual design thinking: the vis kids of architecture. Design Studies, 15,158-174.

Goldschmidt, G. (1995) Visual displays for design: imagery, analogy and databases of visual images. Visual databases in architecture: recent advances in design and decision-making eds A. Koutamanis, H. Timmermans and I. Vermeulen, pp. 53-76. Avebury, Aldershot, UK. 
Goldschmidt, G. (1998) Creative Architectural Design: Reference versus Precedence. Journal of Architecture and Planning Research, 15, 258-270.

Hammersley, M. and Atkinson, P. (1995) Ethnography: Principles in Practice. Routledge, London.

Hillier, W., Musgrove, J. and 0'Sullivan, P. (1972) Knowledge and Design. Environmental Design: Research and Practice ed W.J. Mitchell. University of California, Los Angeles, CA. Reprinted in Developments in Design Methodology ed N.G. Cross, pp. 245-264. John Wiley, Chichester, UK.

Jansson, D.G. and Smith, S.M. (1991) Design fixation. Design Studies, 12, 3-11.

McDermott, C. (1999) Vivienne Westwood. Carlton, London.

McFadzean, J., Cross, N.G. and Johnson, J.H. (1999) Notation and Cognition in Conceptual Sketching. Proceedings of VR'99, Visual and Spatial Reasoning in Design. MIT Press, Cambridge, MA.

Oxman, R.E. (1990) Prior knowledge in design: a dynamic knowledge-based model of design and creativity. Design Studies, 11, 17-28.

Oxman, R.E. and Oxman, R.M. (1992) Refinement and adaptation in design cognition. Design Studies, 13, 117-134.

Purcell A.T. and Gero J.S. (1996) Design and other types of fixation. Design Studies, 17, 363-383

Purcell, A.T. and Gero J.S. (1998) Drawings and the design process. Design Studies, 19, 389-430.

Scaife, M., Curtis, E., and Hill, C. (1994) Interdisciplinary collaboration: a case study of software development for fashion designers. Interacting with Computers, 6, 395-410.

Schön, D.A. (1983) The Reflective Practitioner: How Professionals Think in Action Basic Books, New York.

Schön, D.A. (1988) Designing: Rules, types and worlds. Design Studies, 9, 181-190.

Schön D.A. and Wiggins, G.A. (1992) Kinds of seeing and their function in designing. Design Studies, 13, 135-156.

Simon, H.A. (1996) Sciences of the Artificial 3rd ed. MIT Press, Cambridge, MA.

Smithers, T. (1996) On knowledge level theories of design process. Artificial Intelligence in Design '96 eds J S Gero \& F Sudweeks, pp. 561-579. Kluwer Academic Publishers, Dordrecht, Netherlands.

Smithers, T. (1998) Towards knowledge level theories of design process. Artificial Intelligence in Design '98 eds J S Gero \& F Sudweeks, pp. 3-21. Kluwer Academic Publishers, Dordrecht, Netherlands.

Spencer, D. (1989) Knitting Technology Butterworth-Heinemann, Oxford, UK.

Stacey, M.K. and Eckert, C.M. (1999) An Ethnographic Methodology for Design Process Analysis. Proceedings of the 12th International Conference on Engineering Design, vol. 3, pp. 1565-1570. Technical University of Munich, Munich, Germany.

Stacey, M.K. and Eckert, C.M. (2003) Against Ambiguity. Computer Supported Cooperative Work, 12, 153-183.

Stacey, M.K., Eckert C.M. and McFadzean, J. (1999) Sketch Interpretation in Design Communication. Proceedings of the 12th International Conference on Engineering Design, vol. 2 pp. 923-928. Technical University of Munich, Munich, Germany.

Suchman, L.A. (1987) Plans and Situated Actions. Cambridge University Press, Cambridge, UK.

Visser, W. (1990) More or less following a plan during design: opportunistic deviations in specification. International Journal of Man-Machine Studies, 33, 247-278. 
Visser, W. (1992) Designers' activities examined at three levels: organization, strategies and problem-solving processes. Knowledge-Based Systems, 5, 92-104.

Visser, W. (1994) The organisation of design activities: opportunistic, with hierarchical episodes. Interacting with Computers, 6, 235-274. 